DOI 10. 18307/2015. 0625

(C) 2015 by Journal of Lake Sciences

\title{
西藏尼洋河水环境特征多元统计分析”
}

\author{
刘海平 ${ }^{1,2,3}$, 钟国辉 ${ }^{1}$, 叶少文 ${ }^{2}$, 张良松 ${ }^{4}$, 张惠娟 ${ }^{1}$, 范丽卿 ${ }^{1}$, 巴 桑 ${ }^{1}$, 李钟杰 ${ }^{2 * *}$ \\ $(1:$ 西藏大学农牧学院, 林芝 860000$)$ \\ (2: 中国科学院水生生物研究所淡水生态与生物技术国家重点实验室,武汉 430072) \\ (3: 中国科学院大学, 北京 100049) \\ ( 4 : 福建省水产技术推广总站,福州 350003 )
}

摘 要: 自 2008 年 11 月到 2009 年 10 月按照月份监测西藏林芝地区尼洋河水环境特征. 结果显示, 根据 Pearson 相关性 矩阵, 可将尼洋河 26 项理化指标分为 3 大类, 分别是低度相关性理化指标、中度相关性理化指标和高度相关性理化因子. 析因分析显示, 可将 26 项理化指标分为 4 大类, 第 1 类为尼洋河水体常规的理化指标、第 2 类为尼洋河水体硬度相关指 标、第 3 类为海拔及第 4 类为影响水生生物生长的水质理化指标. PCA 分析发现, 平水期、丰水期以及枯水期水环境特征 明显不同, 以上 3 期各自聚为一类, 而尼洋河沿程方面, 水环境特征则不存在差异. 构建了尼洋河海拔、底层水温与相关理 化因子的一元回归方程. 建议加强对尼洋河水环境的监测工作, 积极推进尼洋河水域生态环境的可持续发展进程.

关键词: 西藏; 尼洋河; 水质理化; 时空动态; 主成分分析; 析因分析;Pearson 相关性矩阵

\section{Multivariate statistical analysis of water environment for Niyang River, the branch of the Yarlung Zangbo River, Tibet}

LIU Haiping ${ }^{1,2,3}$, ZHONG Guohui ${ }^{1}$, YE Shaowen ${ }^{2}$, ZHANG Liangsong $^{4}$, ZHANG Huijuan $^{1}$, FAN Liqing $^{1}$, BA Sang $^{1}$ \& LI Zhongjie ${ }^{2}$

(1: Agricultural and Animal Husbandry College of Tibet University, Linzhi 860000 , P. R. China)

(2: State Key Laboratory of Freshwater Ecology and Biotechnology, Institute of Hydrobiology, Chinese Academy of Sciences, Wuhan 430072 , P. R. China)

(3: University of Chinese Academy of Sciences, Beijing 100049, P. R. China)

(4: Fujian Marine Products Technical Promotion Station, Fuzhou 350003, P. R. China)

Abstract: We have monitored and analyzed water environment for Niyang River, the branch of the Yarlung Zangbo River, Tibet, based on seasons from November 2008 to October 2009. The results are as follows: Firstly, based on Pearson correlation matrix, physico-chemical factors for Niyang River can be divided into three categories, which are low correlation physicochemical factors, mid correlation physico-chemical factors and high correlation physico-chemical factors. Secondly, based on factorial analysis, physicochemical factors for Niyang River can be divided into four categories, which are normal physico-chemical factors, hardness relevant physico-chemical factors, elevation, and physicochemical factors affecting growth of aquatic organism. Thirdly, based on PCA, the characteristics of level period, wet season and dry season are significantly different, there is no difference along Niyang River from upstream to downstream. Last but not least, we have structured regression equation between elevation and relevant physicochemical factors, regression equation between bottom water temperature and relevant physicochemical factors. The paper also suggests paying close attention to water environment monitoring, in order to warrantee the sustainable development of Niyang River aquatorium ecology.

Keywords: Tibet; Niyang River; physico-chemical characteristics; spatio-temporal dynamic; PCA; factorial analysis; Pearson

* 西藏科技厅地区基金重点项目、西藏财政厅农业技术推广项目、农业部公益性行业专项 (201403012) 和国家自然 科学基金项目 (31160140) 联合资助. 2015-05-26 收稿;2015-07-20 收修改稿. 刘海平(1981 ), 男, 博士, 副教 授;E-mail:luihappying@163.com.

** 通信作者;E-mail: zhongjie@ ihb. ac. cn. 
correlation matrix

青藏高原素有“亚洲水塔”之誉, 是亚洲十大河流之源, 湖泊星罗密布, 河流纵横交错, 由于受到强烈的 地质条件的影响以及独特的气候作用, 特别是高原地区, 高海拔区域的气候变暖效应较低海拔区域明显, 由 于海拔所引起的气候变暖效应能够加速改变高山生态系统、水生态系统的生物多样性 ${ }^{[1]}$, 随着全球气候变 暖, 青藏高原冰雪融量以及降水量都在发生改变, 导致湖面水位升高和河流径流量增大 ${ }^{[2]}$, 这些水源的补给 将影响和改变水环境特征 ${ }^{[3]}$, 从而间接影响水生生物群落结构和水体的生态服务功能, 同时, 随着水温的升 高, 将影响河流水生生物的分布、数量以及水体的健康 ${ }^{[4]}$. 除此之外, 社会发展和人为干扰因子的存在, 高原 河流、湖泊正在遭受着一系列现实的问题, 如: 流域用水总量不断上升、污染排放总量持续增加、流域主要水 体水质不断恶化 ${ }^{[5]}$, 丁海容 ${ }^{[6]}$ 在对拉萨市城区段水环境进行监测发现, 由于拉萨市区内大量未经处理的生 活污水及工业废水直排到中干渠, 再由中干渠在拉鲁湿地出口全部汇人流沙河, 导致流沙河水质现状较差, 部分水质超过《地表水环境质量标准》(GB 3838-2002) III 类水质标准, COD 污染超标严重, 最大倍数达 17.5 倍. 可见, 长期坚持开展高原河流、湖泊的水环境监测工作, 不论是从科学研究价值还是社会现实意义 角度, 都显得尤为重要. 本文通过对尼洋河水环境特征的分析, 判断尼洋河各类水质理化指标之间的相关 性, 建立水温、海拔与相关理化指标的一元回归方程, 从而为尼洋河水环境的监测提供科学的理论依据, 为 尼洋河水域生态的可持续发展提供理论基础,也为鱼类保护、水电站建设评估提供科学依据.

\section{1 实验设计和数据处理}

关于研究区域概况、采站设置、采样时间等内容参考同系列文章 ${ }^{[7-9]}$, 水体理化指标采集和分析方法具 体参见表 1 .

表 1 尼洋河水体水质理化指标及代码、单位、保存方法和分析方法

Tab. 1 Physico-chemical parameter, code, unit, anylasis method and water sample presearved method

\begin{tabular}{|c|c|c|c|c|}
\hline 水体理化指标 & 代码 & 单位 & 保存方法 & 分析方法 \\
\hline 表层水温 & $\mathrm{WT}_{\mathrm{S}}$ & ${ }^{\circ} \mathrm{C}$ & - & CX-401 现场测定 \\
\hline 底层水温 & $\mathrm{WT}_{\mathrm{B}}$ & ${ }^{\circ} \mathrm{C}$ & - & CX-401 现场测定 \\
\hline 气温 & $\mathrm{T}$ & ${ }^{\circ} \mathrm{C}$ & - & CX-401 现场测定 \\
\hline $\mathrm{pH}$ 值 & $\mathrm{pH}$ & 无量纲 & - & CX-401 现场测定 \\
\hline 硬度 & $\mathrm{TH}$ & ${ }^{\circ} \mathrm{DH}$ & 文献 $[10]$ & 由 $\mathrm{CaCO}_{3}$ 计算 \\
\hline 镁离子 & $\mathrm{Mg}^{2+}$ & $\mathrm{mg} / \mathrm{L}$ & 文献 $[10]$ & GB $11905-1989$ \\
\hline 钲 & $\mathrm{Ca}$ & $\mathrm{mg} / \mathrm{L}$ & 文献 $[10]$ & GB $11905-1989$ \\
\hline 钠离子 & $\mathrm{Na}^{+}$ & $\mathrm{mg} / \mathrm{L}$ & 文献 $[10]$ & GB $11904-1989$ \\
\hline 钾离子 & $\mathrm{K}^{+}$ & $\mathrm{mg} / \mathrm{L}$ & 文献 $[10]$ & GB $11904-1989$ \\
\hline 铁 & $\mathrm{Fe}$ & $\mathrm{mg} / \mathrm{L}$ & 文献 [10] & 文献 [10],2002 \\
\hline 硝酸根 & $\mathrm{NO}_{3}^{-}$ & $\mathrm{mg} / \mathrm{L}$ & 文献 $[10]$ & GB $7480-1987$ \\
\hline 硫酸根 & $\mathrm{SO}_{4}^{2-}$ & $\mathrm{mg} / \mathrm{L}$ & 文献 $[10]$ & GB $13196-1991$ \\
\hline 碳酸氢根 & $\mathrm{HCO}_{3}^{-}$ & $\mathrm{mg} / \mathrm{L}$ & 文献 $[10]$ & 文献 [10],2002 \\
\hline 氯离子 & $\mathrm{Cl}^{-}$ & $\mathrm{mg} / \mathrm{L}$ & 文献 $[10]$ & $\mathrm{HJ} / \mathrm{T} 84-2001$ \\
\hline 硅酸根 & $\mathrm{SiO}_{3}^{2-}$ & $\mathrm{mg} / \mathrm{L}$ & 文献 $[10]$ & 文献 $[10], 2002$ \\
\hline 矿化度 & TDS & $\mathrm{mg} / \mathrm{L}$ & 文献 $[10]$ & 文献 $[10], 2002$ \\
\hline 化学耗氧量 & COD & $\mathrm{mg} / \mathrm{L}$ & 文献 $[10]$ & GB $11914-1989$ \\
\hline 表层溶解氧 & $\mathrm{DO}_{\mathrm{s}}$ & $\mathrm{mg} / \mathrm{L}$ & 文献 $[10]$ & GB 7489- 1987 \\
\hline 底层溶解氧 & $\mathrm{DO}_{\mathrm{B}}$ & $\mathrm{mg} / \mathrm{L}$ & 文献 $[10]$ & GB $7489-1987$ \\
\hline 叶绿素 a & Chl. a & $\mathrm{mg} / \mathrm{L}$ & 文献 [10] & SL $88-1994$ \\
\hline 总氮 & $\mathrm{TN}$ & $\mathrm{mg} / \mathrm{L}$ & 文献 $[10]$ & GB $11894-1989$ \\
\hline 总磷 & $\mathrm{TP}$ & $\mathrm{mg} / \mathrm{L}$ & 文献 $[10]$ & GB $11893-1989$ \\
\hline 硫化物 & $S^{2-}$ & $\mathrm{mg} / \mathrm{L}$ & 文献 $[10]$ & GB/T 16489-1996 \\
\hline 总碱度 & $\mathrm{TA}$ & $\mathrm{mg} / \mathrm{L}$ & 文献 $[10]$ & 文献 $[10], 2002$ \\
\hline 铵态氮 & $\mathrm{NH}_{4}^{+}-\mathrm{N}$ & $\mathrm{mg} / \mathrm{L}$ & 文献 $[10]$ & GB $7479-1987$ \\
\hline
\end{tabular}

通过 SPSS 18.0 建立尼洋河水质理化指标 Pearson 相关性矩阵, 用析因分析方法探析尼洋河水质理化主 
要解释指标, 构建海拔、底层水温与相关理化因子的一元回归方程. 基于 R 语言 (版本号:2.14.1), 用 PCA 方法 (principal component analysis) 对尼洋河水质理化指标时空特征进行分析.

\section{2 结果与分析}

\section{1 尼洋河水体理化指标相关性分析}

选择 26 项水体理化指标以及采样点海拔信息, 采用 Pearson 相关性矩阵, 探析尼洋河水体理化因子之 间的相关性,结果显示 (表 2), 在 26 项水体理化指标信息中, 显著相关项 $(P<0.05)$ 在 10 项以下的指标有 11 项,包括: 铵态氮、硬度、铁、pH 值、镁、海拔、钲、底层溶解氧、总氮、矿化度和表层溶解氧, 可以将它们称为 低度影响尼洋河水体理化性质相关因子, 其中, 与海拔相关的指标有硬度、钙、碳酸氢根、硅酸根、叶绿素 $\mathrm{a}$ 以及总碱度 6 项. 显著相关项 $(P<0.05)$ 在 $10 \sim 15$ 项的理化因子有 9 项, 包括氯离子、总磷、气温、硝酸根、 硫化物、化学耗氧量、钠、碳酸氢根和碱度, 可以将它们称为中度影响尼洋河水体理化性质相关因子. 显著相 关项 $(P<0.05)$ 在 15 项以上的理化因子有 6 项, 包括硅酸根、钾、叶绿素 $\mathrm{a} 、$ 表层温度、底层温度以及硫酸根, 可以将它们称为高度影响尼洋河水体理化性质相关因子, 显著相关项最多的是底层温度, 达 22 项.

\section{2 尼洋河水体理化指标析因分析}

用析因分析法分析尼洋河水质理化指标特征, 经最大四次方值法旋转平方和之后, 前 8 个主成分累计 贡献率达 $84.89 \%$, 可将 26 项水质理化指标归纳为 4 类:第 1 类为尼洋河水体常规监测的理化指标, 如主成 分 1 和主成分 2 所展示,包括: 水体的底层温度、表层温度、气温、钠离子、钾离子、硝酸根、硫酸根、碳酸氢根、 氯离子、化学耗氧量、硅酸根、表层溶解氧、底层溶解氧、叶绿素 $\mathrm{a} 、$ 总氮、硫化物、碱度和铵态氮等 18 项理化 指标; 第 2 类如主成分 3 所展示, 为尼洋河水体的硬度相关指标, 包括: 硬度和钻; 第 3 类为海拔, 即主成分 4 ;第 4 类为影响水生生物生长的水质理化指标,如主成分 5 、主成分 6 和主成分 7 所示,包括 $\mathrm{pH}$ 值、总磷、矿 化度、镁和铁 5 项理化指标 (表 $3 、$ 表 4).

\section{3 尼洋河水体理化性质时空特征分析}

通过 PCA 解释尼洋河水体理化性质时空特征, 前两个主成分解释率之和达 $48.7 \%$. 尼洋河沿程方面, 水体 的理化性质较为相似, 河道底质方面, 流经砂石和粘土的尼洋河水体理化性质也较为相似, 但是在季节方面, 出现较大的变动, 主要表现在冬季和春季 (枯水期) 的尼洋河水体理化性质归为一类, 夏季 (丰水期)和秋季 (平水期) 的尼洋河水体理化性质各为一类, 尼洋河水体理化性质与季节存在极大的关联 (图 1).

\section{4 尼洋河水体海拔、底层温度与相关理化因子一元回归方程构建}

海拔决定一个地区的温度和光照等环境因素的变化, 属于宏观尺度的环境因子, 通常情况下, 由于海拔 的升高, 水域温度降低, 冰冻期延长 ${ }^{[1-12]}$, 物种的丰富度也随之降低 ${ }^{[13]}$, 可见, 海拔和温度对水环境的影响较 大, 但尼洋河水体的海拔与温度不存在显著相关性 (表 2), 同时, 为了探究尼洋河海拔与其他相关理化因子 的具体关系, 构建了尼洋河海拔与相关理化因子的一元回归方程, 尼洋河可与海拔构建一元回归方程的理 化因子有水体硬度、钙、碳酸氢根、硅酸根和叶绿素 $\mathrm{a}$, 且均为正相关, 所构建的一元回归方程关系显著 $(P<$ 0.05 ) (图 2). 选择底层温度与相关理化因子构建一元回归方程, 这些相关理化因子有表层温度、气温、 $\mathrm{pH}$ 值、钠离子、钾离子、硝酸根、硫酸根、碳酸氢根、氯离子、硅酸根、矿化度、化学耗氧量、表层溶解氧、底层溶解 氧、叶绿素 $\mathrm{a} 、$ 硫、总碱度和铵态氮等 18 项理化指标, 所构建的一元回归方程关系显著 $(P<0.05)$, 其中, 与底 层水温呈负相关的理化因子有碳酸氢根、矿化度、表层溶解氧、底层溶解氧、总碱度 5 项理化因子, 其余 13 项 理化因子与底层水温均呈正相关 (图 3).

\section{3 讨论}

\section{1 尼洋河水生生物及环境季节变化基本特征及原因探析}

水环境的稳定性随着水体中离子组成及比例的变化而变化 ${ }^{[14]}$, 水体中离子的来源 $(C)$ 有: 流域内岩石 风化产物 $\left(C_{\mathrm{w}}\right)$ 、人为因素贡献 $\left(C_{\mathrm{anth}}\right)$ 、大气降水 $\left(C_{\mathrm{dry}}\right)$ 、大气干沉降 $\left(C_{\mathrm{wet}}\right)$ 、生物圈贡献 $\left(C_{\mathrm{bio}}\right)$ 和物质再循环 过程中的净迁移量 $\left(C_{\text {exch }}\right)^{[15]}$, 可表示为:

$$
C=C_{\mathrm{w}}+C_{\mathrm{anth}}+C_{\mathrm{dry}}+C_{\mathrm{wet}}+C_{\mathrm{bio}}+C_{\mathrm{exch}}
$$




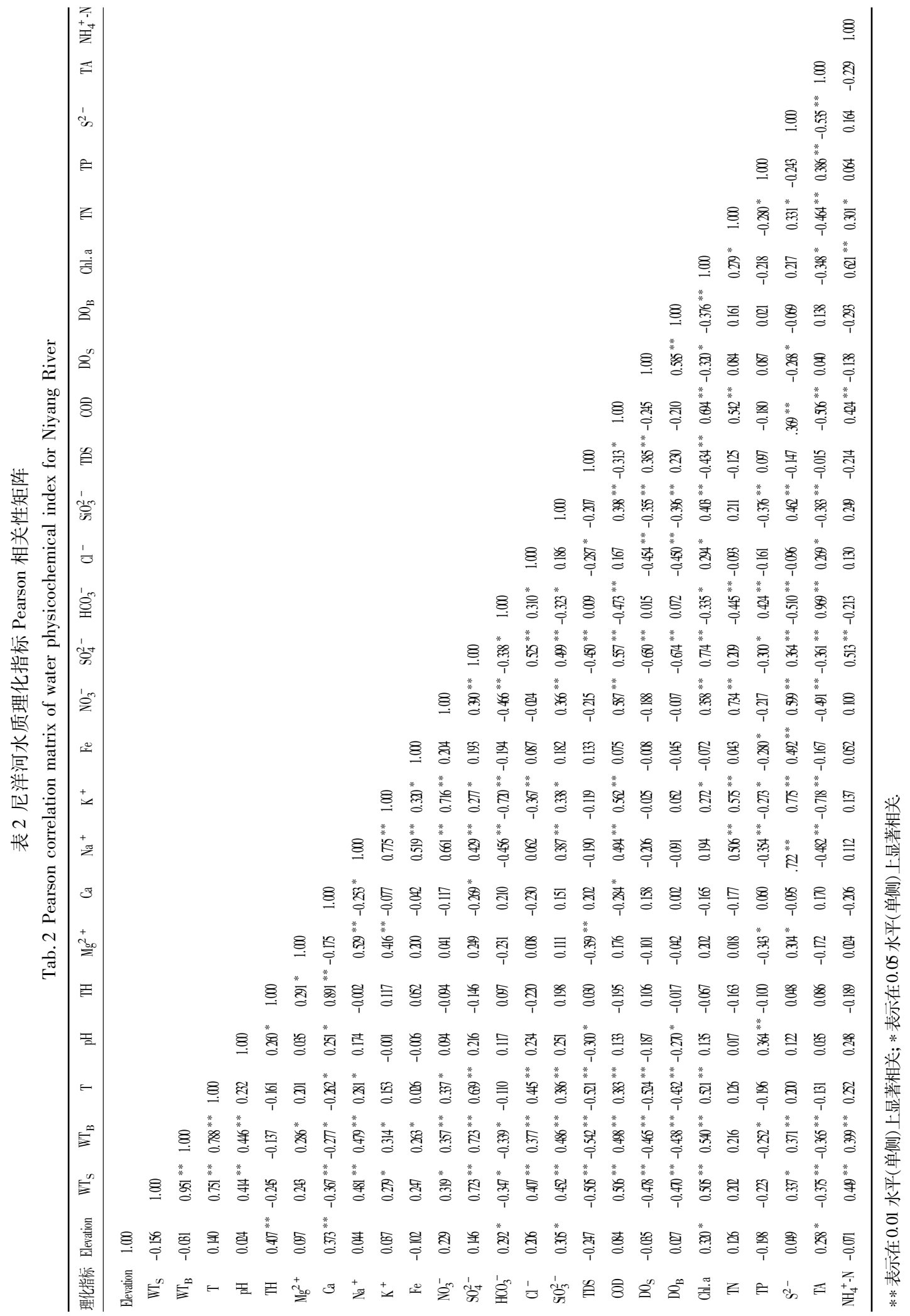


表 3 尼洋河水质理化指标总方差分解

Tab. 3 Total variance explanations for physico-chemical factors of water quality index for Niyang River

\begin{tabular}{|c|c|c|c|c|c|c|c|c|c|}
\hline \multirow[b]{2}{*}{ 理化指标 } & \multicolumn{3}{|c|}{ 初始特征值 } & \multicolumn{3}{|c|}{ 提取平方和载人 } & \multicolumn{3}{|c|}{ 旋转平方和载人 } \\
\hline & 合计 & $\begin{array}{l}\text { 方差百 } \\
\text { 分比 } \%\end{array}$ & $\begin{array}{l}\text { 累积百 } \\
\text { 分比/\% }\end{array}$ & 合计 & $\begin{array}{l}\text { 方差百 } \\
\text { 分比 } \%\end{array}$ & $\begin{array}{l}\text { 累积百 } \\
\text { 分比 } \%\end{array}$ & 合计 & $\begin{array}{l}\text { 方差百 } \\
\text { 分比 } / \%\end{array}$ & $\begin{array}{l}\text { 累积百 } \\
\text { 分比 } / \%\end{array}$ \\
\hline Elevation & 8.258 & 31.761 & 31.761 & 8.258 & 31.761 & 31.761 & 6.146 & 23.638 & 23.638 \\
\hline $\mathrm{WT}_{\mathrm{S}}$ & 3.936 & 15.140 & 46.902 & 3.936 & 15.140 & 46.902 & 5.457 & 20.987 & 44.625 \\
\hline $\mathrm{WT}_{\mathrm{B}}$ & 2.562 & 9.853 & 56.755 & 2.562 & 9.853 & 56.755 & 2.422 & 9.314 & 53.939 \\
\hline $\mathrm{T}$ & 1.775 & 6.828 & 63.583 & 1.775 & 6.828 & 63.583 & 1.873 & 7.204 & 61.143 \\
\hline $\mathrm{pH}$ & 1.610 & 6.194 & 69.777 & 1.610 & 6.194 & 69.777 & 1.738 & 6.684 & 67.828 \\
\hline TH & 1.425 & 5.481 & 75.258 & 1.425 & 5.481 & 75.258 & 1.623 & 6.244 & 74.072 \\
\hline $\mathrm{Mg}^{2+}$ & 1.238 & 4.763 & 80.021 & 1.238 & 4.763 & 80.021 & 1.547 & 5.949 & 80.021 \\
\hline $\mathrm{Ca}$ & 0.975 & 3.750 & 83.771 & & & & & & \\
\hline $\mathrm{Na}^{+}$ & 0.850 & 3.270 & 87.040 & & & & & & \\
\hline $\mathrm{K}^{+}$ & 0.590 & 2.270 & 89.310 & & & & & & \\
\hline $\mathrm{Fe}$ & 0.496 & 1.907 & 91.217 & & & & & & \\
\hline $\mathrm{NO}_{3}^{-}$ & 0.451 & 1.733 & 92.950 & & & & & & \\
\hline $\mathrm{SO}_{4}^{2^{-}-}$ & 0.388 & 1.492 & 94.442 & & & & & & \\
\hline $\mathrm{HCO}_{3}^{-}$ & 0.334 & 1.283 & 95.725 & & & & & & \\
\hline $\mathrm{Cl}^{-}$ & 0.321 & 1.236 & 96.961 & & & & & & \\
\hline $\mathrm{SiO}_{3}^{2-}$ & 0.188 & 0.725 & 97.686 & & & & & & \\
\hline TDS & 0.145 & 0.558 & 98.244 & & & & & & \\
\hline COD & 0.117 & 0.451 & 98.695 & & & & & & \\
\hline $\mathrm{DO}_{\mathrm{s}}$ & 0.099 & 0.381 & 99.076 & & & & & & \\
\hline $\mathrm{DO}_{\mathrm{B}}$ & 0.079 & 0.304 & 99.381 & & & & & & \\
\hline Chl. a & 0.059 & 0.226 & 99.606 & & & & & & \\
\hline TN & 0.038 & 0.146 & 99.752 & & & & & & \\
\hline $\mathrm{TP}$ & 0.027 & 0.105 & 99.857 & & & & & & \\
\hline$S^{2-}$ & 0.023 & 0.090 & 99.947 & & & & & & \\
\hline TA & 0.014 & 0.053 & 100.000 & & & & & & \\
\hline $\mathrm{NH}_{4}^{+}-\mathrm{N}$ & 0 & 0 & 100.000 & & & & & & \\
\hline
\end{tabular}

表 4 尼洋河水质理化指标旋转主成分矩阵*

Tab. 4 Rotated principal component matrix of water physico-chemical factors for Niyang River

\begin{tabular}{|c|c|c|c|c|c|c|c|}
\hline \multirow{2}{*}{ 理化指标 } & \multicolumn{7}{|c|}{ 主成分 } \\
\hline & 1 & 2 & 3 & 4 & 5 & 6 & 7 \\
\hline Elevation & 0.097 & 0.131 & 0.469 & 0.736 & -0.207 & -0.210 & 0.049 \\
\hline $\mathrm{WT}_{\mathrm{S}}$ & 0.813 & 0.260 & -0.198 & -0.172 & 0.089 & 0.172 & 0.188 \\
\hline $\mathrm{WT}_{\mathrm{B}}$ & 0.806 & 0.293 & -0.094 & -0.100 & 0.080 & 0.165 & 0.240 \\
\hline $\mathrm{T}$ & 0.764 & 0.134 & -0.133 & 0.156 & -0.044 & 0.027 & 0.185 \\
\hline $\mathrm{pH}$ & 0.377 & 0.037 & 0.296 & 0.025 & 0.039 & 0.778 & 0.062 \\
\hline TH & -0.133 & -0.038 & 0.930 & 0.057 & 0.056 & 0.038 & 0.250 \\
\hline $\mathrm{Mg}^{2+}$ & 0.163 & 0.174 & 0.101 & -0.062 & 0.129 & -0.168 & 0.866 \\
\hline $\mathrm{Ca}$ & -0.214 & -0.122 & 0.910 & 0.088 & -0.003 & 0.119 & -0.154 \\
\hline $\mathrm{Na}^{+}$ & 0.262 & 0.726 & -0.049 & 0.037 & 0.450 & 0.012 & 0.290 \\
\hline $\mathrm{K}^{+}$ & 0.020 & 0.892 & 0.109 & -0.191 & 0.132 & -0.033 & 0.238 \\
\hline $\mathrm{Fe}$ & 0.128 & 0.263 & 0.018 & -0.089 & 0.744 & -0.076 & 0.015 \\
\hline $\mathrm{NO}_{3}^{-}$ & 0.182 & 0.868 & -0.043 & 0.248 & 0.062 & 0.032 & -0.120 \\
\hline $\mathrm{SO}_{4}^{2-}$ & 0.889 & 0.265 & -0.021 & -0.035 & -0.060 & -0.136 & 0.006 \\
\hline $\mathrm{HCO}_{3}^{-}$ & -0.118 & -0.669 & 0.019 & 0.620 & 0.047 & 0.272 & -0.064 \\
\hline $\mathrm{Cl}^{-}$ & 0.675 & -0.270 & -0.185 & 0.414 & 0.128 & -0.086 & -0.114 \\
\hline $\mathrm{SiO}_{3}^{2-}$ & 0.554 & 0.373 & 0.423 & -0.007 & 0.091 & -0.144 & -0.143 \\
\hline TDS & -0.514 & -0.100 & 0.073 & -0.276 & 0.259 & -0.160 & -0.527 \\
\hline COD & 0.441 & 0.653 & -0.129 & -0.006 & -0.281 & -0.003 & -0.009 \\
\hline $\mathrm{DO}_{\mathrm{S}}$ & -0.729 & 0.054 & 0.019 & -0.077 & -0.158 & 0.028 & 0.048 \\
\hline $\mathrm{DO}_{\mathrm{B}}$ & -0.767 & 0.171 & -0.181 & 0.211 & -0.039 & 0.010 & 0.180 \\
\hline Chl. a & 0.648 & 0.345 & 0.055 & 0.013 & -0.525 & -0.136 & 0.049 \\
\hline $\mathrm{TN}$ & -0.009 & 0.818 & -0.161 & 0.169 & -0.199 & -0.003 & -0.109 \\
\hline $\mathrm{TP}$ & -0.210 & -0.280 & -0.101 & -0.017 & -0.148 & 0.777 & -0.192 \\
\hline$S^{2-}$ & 0.216 & 0.696 & 0.111 & -0.097 & 0.423 & 0.022 & 0.099 \\
\hline TA & -0.162 & -0.688 & -0.024 & 0.603 & 0.042 & 0.216 & 0.016 \\
\hline $\mathrm{NH}_{4}^{+}-\mathrm{N}$ & 0.459 & 0.229 & -0.087 & -0.246 & -0.399 & 0.219 & -0.104 \\
\hline
\end{tabular}

* 取解释率绝对值最大的作为每一个主成分解释程度较高的水质理化指标, 并用加粗来表示. 


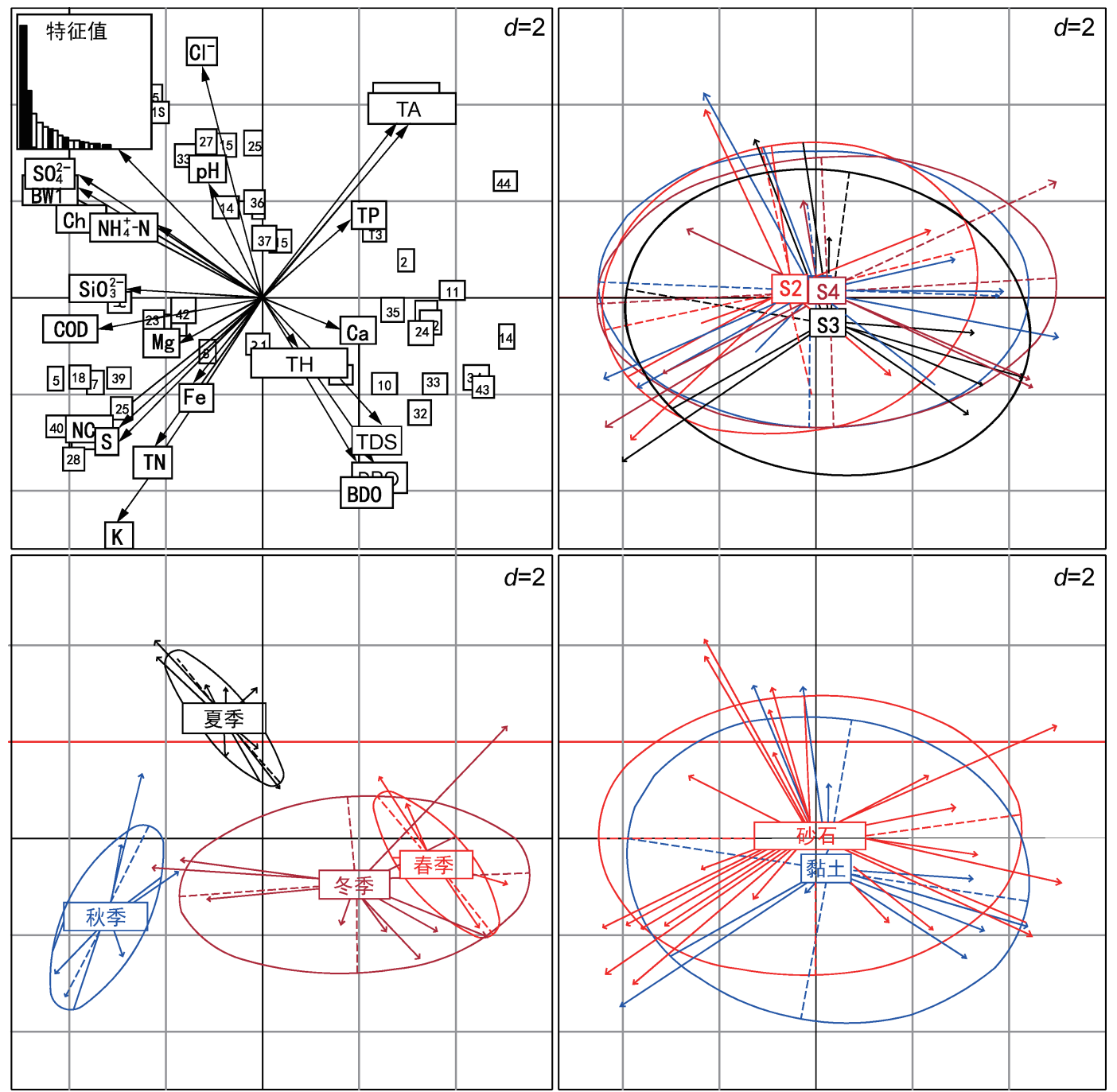

图 1 基于 PCA 分析尼洋河水体理化性质时空特征(图中数字为样点标记, 其中 $1 、 2 、 3 、 4$ 分别为采样点 I 的春、夏、秋、冬季; $5 、 6 、 7 、 8$ 分别为采样点 II 的春、夏、秋、冬季; $9 、 10 、 11 、 12$ 分别为采样点 III 的春、夏、秋、 冬季; $13 、 14 、 15 、 16$ 分别为采样点 IV 的春、夏、秋、冬季. S1 指采样点 I、S2 为采样点 II 、S3 为采样点 III、S4 为采样点 $\mathrm{I}$. 第一主成分解释率为 33.0\% (图中左上图第一条黑色柱所示), 第二主成分解释率为 $15.7 \%$

(图中左上图第二条黑色柱所示), 前两个主成分解释率和达 48.7\% )

Fig. 1 Spatio-temporal character for physico-chemical characteristics for Niyang River based on PCA

青藏高原大部分河流是以钙、碳酸氢根为主的河流, 青藏高原长江源头则以钠离子、氯离子和硫酸根为 主 ${ }^{[16]}$, 在这样的水环境基本框架下, 降水和融雪则是影响青藏高原河流径流量的主要因素 ${ }^{[2]}$. 蒲搸等 ${ }^{[17]}$ 对 丽江盆地水环境特征研究中指出, 季风期丰沛的大气降水输人对河水离子特征有较为显著的影响, Zhang 等 ${ }^{[3]}$ 指出降水对高原湖泊 (纳木错) 的离子和总磷的补给有着重要的作用. 但是, 随着青藏高原气温的逐年 上升, 大量冰雪融水汇人到湖泊或者河流, 截止到 2010 年, 色林错湖面水位由于冰雪融水的输人上升了近 $8 \mathrm{~m}^{[18]}$, 自 1998-2005 年青藏高原部分湖区 (兹格塘错和措那湖) 面积超过了历来最大面积的 $25 \%{ }^{[19]}$. 由于 冰雪中含有丰富的离子和矿物质元素 ${ }^{[20]}$, 也将随着涓涓细流汇人江河, 由于雪水的补给, 流域 ( 内华达山脉 (Sierra Nevada) 附近流域) 中离子 (硝酸根和硫酸根) 的变化呈现出较为显著的时空特征 ${ }^{[21]}$.

尼洋河是以雨水和冰雪融水混合补给的河流 ${ }^{[22]}$, 水环境特征呈现出明显的季节特征. 

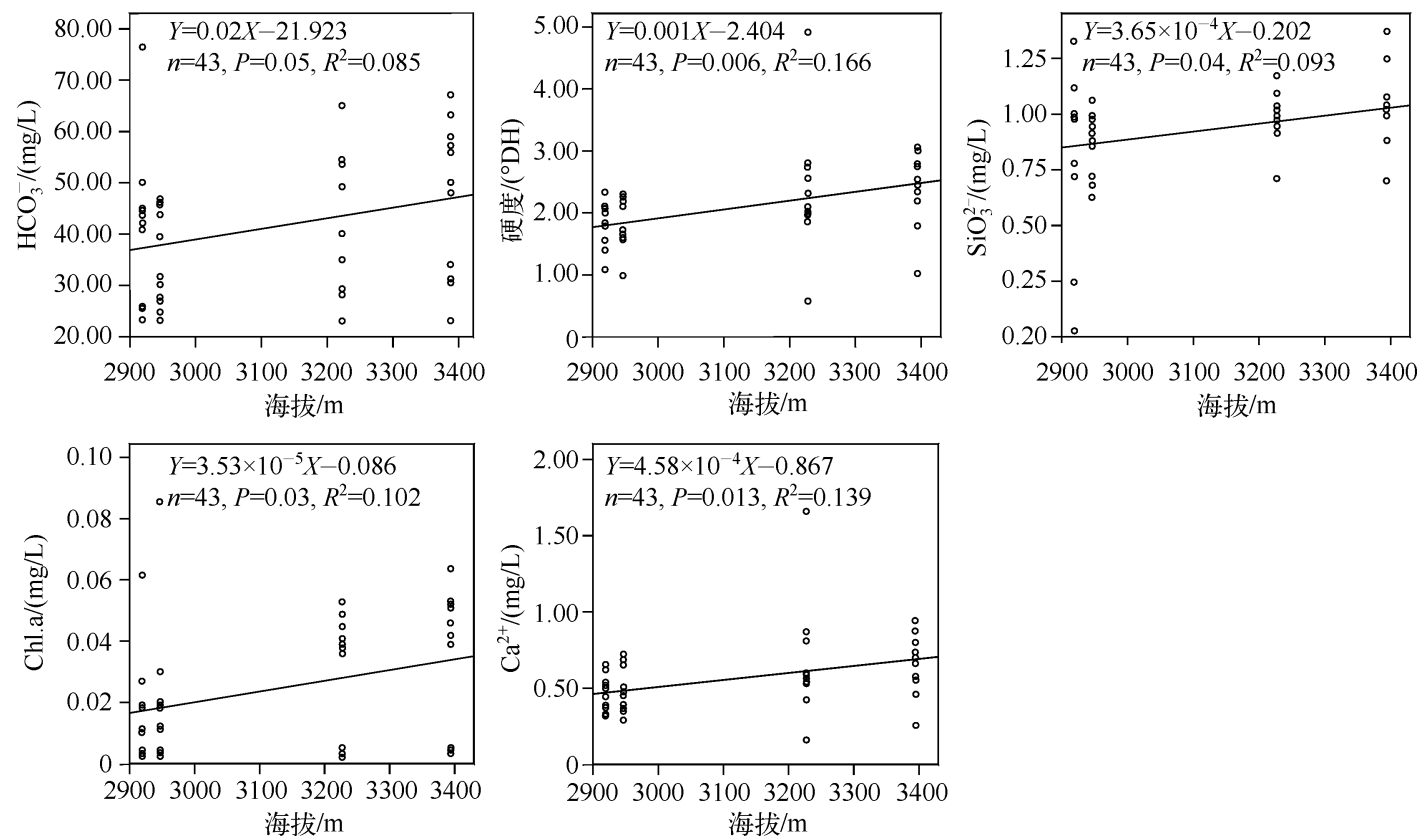

图 2 尼洋河水体海拔与相关理化因子一元回归方程

Fig. 2 Regression equation between elevation and relevant physico-chemical factors for Niyang River

通过 PCA 分析发现, 尼洋河丰水期 (夏季)、平水期 (秋季) 以及枯水期 (冬季和春季) 水环境特征明显不 同, 以上 3 期各自聚为一类,而尼洋河沿程方面, 水环境特征则无差异.

到了冬季, 较雨季而言, 降雨量或者融雪量极大的减少, 河流处于枯水期, 流速降低, 流速会直接影响到 着生藻类的群落结构, 由于水体的冲刷作用, 流速快的地方着生藻类生物量较低, 另外流速与河床的底质存 在着相关性, 流速快的地方底质为砂石, 流速慢的地方底质则为黏土或者细砂, 往往粗糙的基质上着生的着 生藻类物种丰富度较光滑的基质上大, 尼洋河底质为黏土河段的着生藻类物种丰富度和总丰度较底质为砂 石的河段大 ${ }^{[8]}$.

在夏季, 开始有大量的雪融水和天然降水源源不断的输人, 春、夏季比秋、冬季的大型底栖动物总丰度 高 ${ }^{[9]}$. 虽然有营养盐的补给, 但是此时水流较急, 不适宜大量浮游动物生长和繁殖, 导致尼洋河夏季浮游动 物生物量、物种丰富度、总丰度较低, 其中夏季浮游动物物种丰富度、香农指数和均匀度指数最低, 而浮游动 物生物量和总丰度则仅高于冬季 (归处于低温). 河水的交汇导致水体不稳定, 尼洋河浮游动物香农指数和 均匀度指数在 2 个交汇处处于低谷位置.

\section{2 尼洋河水生生物及环境空间变化基本特征及原因探析}

资料显示, 在高海拔山地地带, 海拔升高会放大气候变暖效应, 加速改变高山生态系统、水生态系统的 生物多样性进程 ${ }^{[1]}$. 本研究区域, 尼洋河河源米拉山口海拔逾 $5000 \mathrm{~m}$, 汇人雅鲁藏布江处海拔在 $2900 \mathrm{~m}$ 左 右, 作为高原河流, 与海拔呈显著相关的理化因子有硬度、钙、碳酸氢根、硅酸根、叶绿素 a 以及总碱度 6 项, 且均为正相关,一元线性回归方程显示线性关系显著 $(P<0.05)$, 研究结果未显示海拔与水温之间存在显著 相关.

水温受到很多因素的综合作用. 海拔和河道坡度对水温产生负面影响 ${ }^{[23]}$, Null 等 ${ }^{[4]}$ 研究加州内华达山 脉冷水性河流水温与气候变暖的关系, 发现气温每升高 $2^{\circ} \mathrm{C}$, 水温将升高 $1.6^{\circ} \mathrm{C}$, 同时在春季水温升高幅度最 大, 气温每升高 $2^{\circ} \mathrm{C}$ 水温将升高 $5^{\circ} \mathrm{C}$. 河流形态和融雪因素控制了水温对气温的依赖程度 ${ }^{[24]}$, 融雪通过影响 水体物理和化学性质, 从而影响水生生物的分布和多样性 ${ }^{[25]}$. 

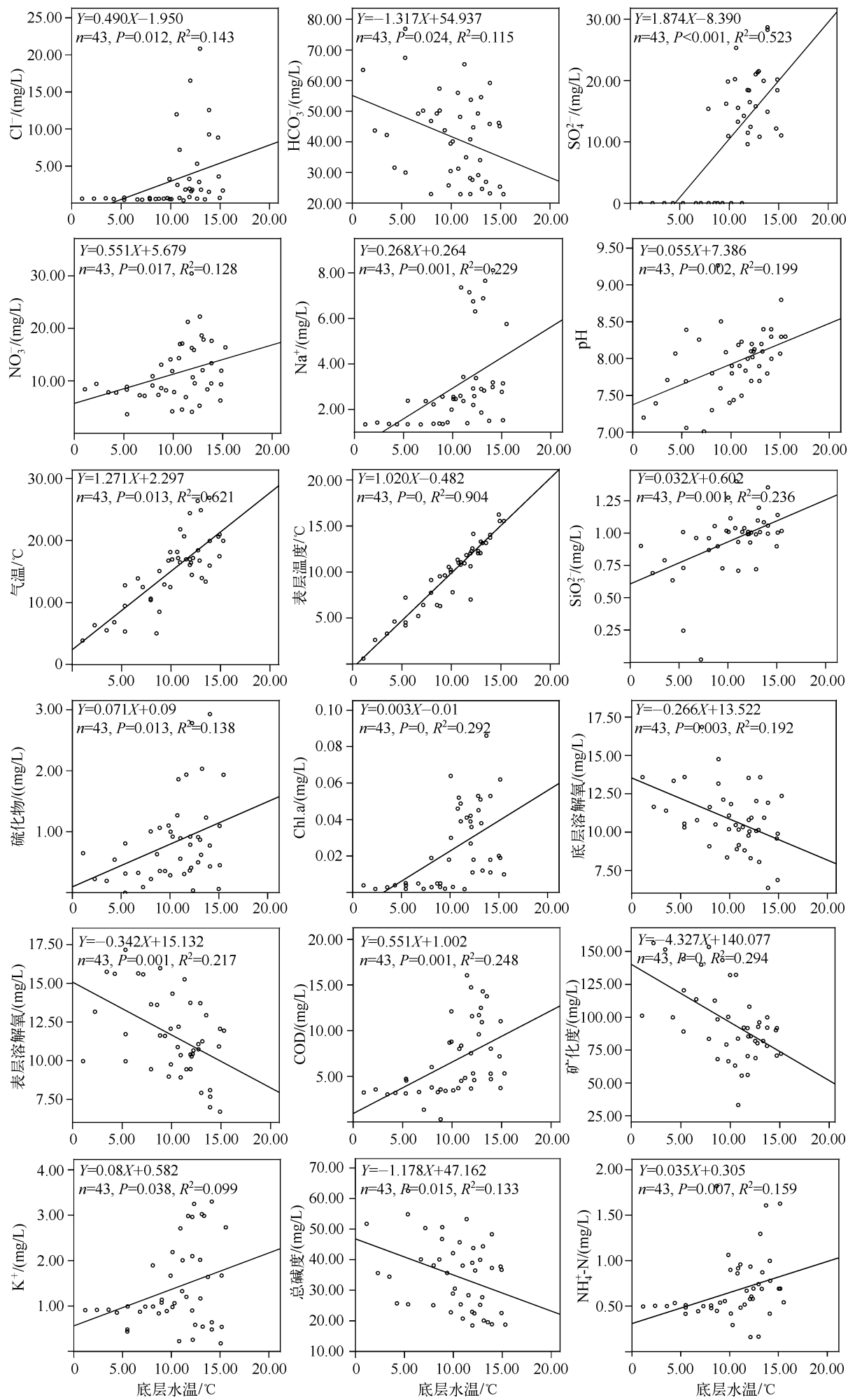

图 3 尼洋河水体底层水温与相关理化因子一元回归方程

Fig. 3 Regression equation between bottom dissolved oxygen and relevant physico-chemical factors for Niyang River 
在本研究中,与底层水温呈显著相关的理化因子有 22 项 (共 26 项检测的理化因子), 相关率高达 84 . $6 \%$,与之呈正相关的理化因子有表层水温、气温、 $\mathrm{pH}$ 值、钠离子、钾离子、硝酸根、硫酸根、氯离子、硅酸根、 化学耗氧量、叶绿素 $\mathrm{a}$ 、硫和铵态氮 13 项, 相关率高达 50\%, 与之呈负相关的理化因子有碳酸氢根、矿化度、 表层溶解氧、底层溶解氧、总碱度 5 项, 以上 18 项指标与底层水温拟合的一元线性回归方程拟合度好 $(P<$ $0.05)$, 其他与之显著相关的理化因子还有钙、镁、铁和总磷, 仅总磷与底层温度呈显著负相关, 其他 3 项均 呈显著正相关. 在设备有限的情况下, 可以通过获取尼洋河底层水温, 计算得知其他理化性质, 有较为广泛 的应用前景,也可为尼洋河水生态长期监测提供理论依据.

尼洋河沿程浮游植物和着生藻类多样性 (香农指数) 特点基本一致, 即: 尼洋河中游藻类香农指数最大, 中上游河段和中下游河段藻类香农指数呈下降趋势 ${ }^{[7-8]}$. 这与 Altormatt 等 ${ }^{[26]}$ 提出的观点一致, 即: 在河流源 头以及高海拔区域, 水生昆虫的 $\alpha$ 多样性最低, 水流汇集区域多的区域, 水生昆虫的物种丰富度也高, 中间 海拔区域群落结构较为复杂.

尼洋河下游较其它河段平缓, 形成了独特的“尼洋河河谷” 风景区, 其河道底质以泥沙和黏土为主, 具有 较大的比表面积, 更容易为浮游植物的生长和繁殖提供各类营养盐, 同时由于河谷河段水流较其他河段平 缓, 减少了因水流给浮游植物带来的生存威胁, 与海拔因素相比, 尼洋河浮游植物物种丰富度或者总丰度对 底质的响应更多一些, 即以泥沙和黏土为底质的河道浮游植物物种丰富度以及总丰度较以砂石为底质的河 道更大 ${ }^{[7]}$.

尼洋河作为雅鲁藏布江 5 大一级支流之一, 在工布地区社会和经济发展过程中发挥着重要的作用, 目 前, 多布电站已在建, 林拉高速即将竣工, 林拉铁路工程正在有条不紊地推进, 由此衍生的采砂场和水泥加 工基地遍地开花, 如何在社会发展过程中保持水生生态系统服务功能, 因此对尼洋河水域生态可持续发展 提出了严峻的挑战. 加强对尼洋河水域生态持续性监测, 及时向有关部门反馈水生态变化信息, 保证尼洋河 流域生态可持续发展, 从而推动社会和经济的区域有序发展,这也是本系列论文的出发点和落脚点.

致谢: 感谢西藏农牧学院动物科学学院强巴央宗院长, 动物科学教研室刘锁珠主任对本项研究工作的全力 支持, 感谢西藏林芝地区农牧局李耿民书记、嘎路副局长对本项研究工作积极配合, 感谢间宏伟、益西曲云、 刘金风、旦增平措同学协助完成水质理化样品的采集工作.

\section{4 参考文献}

[ 1 ] Pepin N, Bradley RS, Diaz HF et al. Elevation-dependent warming in mountain regions of the world. Nature Climate Change, 2015, 5(5): 424-430.

[ 2 ] Bookhagen B, Burbank DW. Toward a complete Himalayan hydrological budget: Spatiotemporal distribution of snowmelt and rainfall and their impact on river discharge. Journal of Geophysical Research, 2010, 115:1-25.

[ 3 ] Zhang YL, Kang SC, Li CL et al. Wet deposition of precipitation chemistry during 2005-2009 at a remote site (Nam Co Station) in central Tibetan Plateau. Journal of Atmospheric Chemistry, 2012, 69(3) : 187-200.

[ 4 ] Null SE, Viers JH, Deas ML et al. Stream temperature sensitivity to climate warming in California's Sierra Nevada: impacts to coldwater habitat. Climatic Change, 2013, 116(S1) : 149-170.

[ 5 ] 李中杰, 郑一新, 张大为等. 滇池流域近 20 年社会经济发展对水环境的影响. 湖泊科学, 2012,24(6):875-882. DOI 10. $18307 / 2012.0610$.

[ 6 ] 丁海容. 拉萨市城区段水环境污染总量控制研究 [ 学位论文].成都:四川大学,2005.

[ 7 ] 刘海平, 叶少文, 杨学峰等. 西藏尼洋河水生生物群落时空动态及与环境因子关系: 1. 浮游植物. 湖泊科学, 2013, 25 (5):695-706. DOI 10. 18307/2013.0511.

[ 8 ] 刘海平, 叶少文, 杨学峰等. 西藏尼洋河水生生物群落时空动态及与环境因子关系:2. 着生藻类. 湖泊科学, 2013, 25 (6) : 907-915. DOI 10. 18307/2013.0615.

[9] 刘海平, 叶少文, 杨学峰等. 西藏尼洋河水生生物群落时空动态及与环境因子关系: 3 . 大型底栖动物. 湖泊科学, 2014 ,26(1) : 154-160. DOI 10. 18307/2014. 0119.

[10] 国家环境保护总局《水和废水监测分析方法》编委会. 水和废水监测分析方法: 第 4 版. 北京: 中国环境科学出版 社, 2002 .

[11] Rundle SD, Jenkins A, Ormerod SJ. Macroinvertebrate communities in streams in Himalaya, Nepal. Freshwater Biology, 
$1993, \mathbf{3 0}(1): 169-180$.

[12] Ao M, Alfred JRB, Gupta A. Studies on some lotic systems in the north-eastern hill regions of India. Limnologica, 1984, $15(1): 135-141$.

[13] Suren AM. Macroinvertebrate communities of streams in western Nepal: effects of altitude and land use. Freshwater Biolo$g y, 1994, \mathbf{3 2}(2): 323-336$.

[14] 王鼎臣. 关于碳酸盐型水质稳定性指数判定法的讨论. 水处理技术, 1994,20(4):219-229.

[15] 何 敏. 小流域风化剥蚀作用及碳侵蚀通量的初步研究 [学位论文]. 昆明:昆明理工大学,2009.

[16] Huang X, Sillanpaa M, Gjessing ET et al. Water quality in the Tibetan Plateau: Major ions and trace elements in the headwaters of four major Asian rivers. Science of the Total Environment, 2009, 407(24) : 6242-6254.

[17] 蒲 搸,何元庆, 朱国锋等. 丽江盆地地表一地下水的水化学特征及其控制因素. 环境科学, 2012,33(1):48-54.

[18] Meng K, Shi XH, Wang E et al. High-altitude salt lake elevation changes and glacial ablation in Central Tibet, 2000 2010. Chinese Science Bulletin, 2012, 57(5) : 525-534.

[19] Liu JS, Wang SY, Yu SM et al. Climate warming and growth of high-elevation inland lakes on the Tibetan Plateau. Global Planet Change, 2009, 67(3/4) : 209-217.

[20] 王 平, 皇翠兰,刘子东. 西藏希夏邦马峰地区雪冰化学特征. 环境科学, 1988,9(1):23-26.

[21] Sickman JO, Melack JM. Nitrogen and sulfate export from high elevation catchments of the Sierra Nevada, California. Water, Air, and Soil Pollution, 1998, 105(1/2) : 217-226.

[22] 关志华,陈传友. 西藏河流与湖泊. 北京:科学出版社, 1984.

[23] Segura C, Caldwell P, Sun G et al. A model to predict stream water temperature across the conterminous USA. Hydrological Processes, 2015, 29(9) : 2178-2195.

[24] Lisi PJ, Schindler DE, Cline TJ et al. Watershed geomorphology and snowmelt control stream thermal sensitivity to air temperature. Geophysical Research Letters, 2015, 42(9) : 3380-3388.

[25] Slemmons KEH, Saros JE, Simon K. The influence of glacial meltwater on alpine aquatic ecosystems : a review. Environmental Science-Processes \& Impacts, 2013, 15(10) : 1794-1806.

[26] Altermatt F, Seymour M, Martinez N. River network properties shape $\alpha$-diversity and community similarity patterns of aquatic insect communities across major drainage basins. Journal of Biogeography, 2013 ,40(12) : 2249-2260. 